\title{
An Evolutionary Take on Humour
}

\section{John Glynn*}

Webster University, Bangkok Campus, Thailand

\begin{abstract}
Despite the common assumption that most times people laugh is in response to a joke, laughter is more often a function of the human need to feel a sense of connection to others, a way of feeling like one belongs. Studying its origin in primates can lend some meaning to the ways humans differ from their predecessors, and can help in the deciphering of the structure of non-human primate societies and how the lack of formal, human humour but the presence of laughter can be used to maintain bonds within a group of individuals. Laughter as a social tool evolved far before the human concept of comedy, functions separately from it, and is very important in maintaining social order as a practice that evolved with humans and became more specialized over time. Laughter behaviourisms are present in many species, including fennec foxes and rats, but in a more strict sense of the word, is a phenomenon particular to the primate world, an inherited practice from the ancestors of humankind that has evolved over time along with the species itself.
\end{abstract}

Keywords: Social; Arts, Science; Humour

\section{Introduction}

The origin of laughter is not with humans, but with a predecessor we share with chimpanzees. Thus, studies of laughter in chimps can be used as insight into another species' use of laughter, especially since the linguistic component that can be dominant with humans is lacking. There is a notable difference between the surface characteristics of chimp laughter and human laughter-chimpanzee laughter appears more like panting and less like the concept of laughter that first comes to one's mind-but both are a vital part in maintaining connections between individuals and particularly in chimpanzees, are important to convey a message that play behaviours' can continue. It is a positive behaviour, encouragement to keep playing and a signal that everything, for the moment, is okay. The variations in this vocalization range from squeaks and pants to more human-like iterations, the most humanlike being that of orang-utans [1]. Orangutan squeaking is less frequent than the noises made by other apes, but it is a sure response to tickling, although the vocalizations are not as lengthy. Laughter is not exclusive to the great apes, and has been found in studies involving tickling rats [2]. This kind of vocalization is much more like chirping than human laughter, but is still valid in the sense that it is evoked from play behaviours and tickling.

This particular vocalization was measured at 50 kilohertz and is distinct from chirps that were made when a rat was playing with a larger rat that had an unfair advantage and made the experience unpleasant. 50 kilohertz chirps were reserved for positive experiences, and seemed to signal happiness for the rats in a way different from any other sound the rats made, as it was consistently found to have positive associations. Even still, when the rats were tickled, they would very clearly display their pleasure by seeking out the gloved hands tickling them and darting towards the hand rather than away. These behaviours were accompanied by the chirps, and may not be a typical example of laughter, but still fits the concept in the context of rats and the way rats are built physiologically. In another study, rats were given a choice to pick from recordings of rat noises, and overwhelmingly, they preferred the 50 kilohertz chirping sounds-another instance where these sounds signalled positivity.

Clearly, this sound is a sign of pleasure and enjoyment, and is one of the more obscure permutations of laughter in species other than humans and apes that have been discovered. The way laughter is present in the great apes, particularly orangutans, is the most similar to the way it is present in humans, and has the most relevance in terms of where the practice of laughter in social contexts originated. Acoustically, there are ties, though in terms of the apes, laughter vocalizations are less present in the exhale, and tend to have less regular vibration of the vocal chords. The differences are evident, but in both cases, laughter is present in play behaviour and as a response to tickling. Through analysis of the acoustic frequency and qualities of the squeaks and other tickle-induced sounds produced by member species of the great apes, the conclusion drawn is that the split between the apes and humans caused laughing behaviourisms to evolve differently, though they can have similar contexts and are societally very prevalent in both. Laughter develops at an early age in humans, though it is debated exactly how early-some say as early as 5 weeks, and others say it is not present until between 6 and 8 weeks [3]. Adversely, smiling makes an appearance much earlier, and is a precursor to laughter. Even as early as preschool, laughter is a social function. A study conducted by Kennerdine in 1931 found that over $90 \%$ of the times pre-schoolers laughed was in the presence of others, meaning that it plays a significant role in communication that is not necessary when the children are alone.

Engaging in humour allows them to build connections and to communicate more effectively, and is important even at those early ages when the conversations children are having are not the same as ones they will typically have when they grow older, in subject topic, style, or dynamic.

As children grow up, they seek out people that make them laugh. Bonds are formed more easily when enjoyment between individuals is made clear, and humor can be like a language in that way-when people are smiling and laughing genuinely, it means that everything is okay. It is very gratifying when one says something intended to procure

*Corresponding author: John Glynn, Webster University, Bangkok Campus, Thailand, Tel: +314-968-6988; E-mail: john.glynn.gev@gmail.com

Received August 23, 2018; Accepted September 06, 2018; Published September 13,2018

Citation: Glynn J (2018) An Evolutionary Take on Humour. Arts Social Sci J 9: 406. doi: 10.4172/2151-6200.1000406

Copyright: @ 2018 Glynn J. This is an open-access article distributed under the terms of the Creative Commons Attribution License, which permits unrestricted use, distribution, and reproduction in any medium, provided the original author and source are credited. 
laughter and it succeeds, and the positive feedback is why the practice prevails [4]. Positive reinforcement as a response to human behaviour is a way to be sure it will stick around. This is the way that laughter is important, since it is gratifying to both parties, it plays into the need for approval of both parties and is doubly effective. The gratification granted by such interactions is a bonding agent that tips the scale in favour of those who know how to use humour effectively. The principle of reciprocal liking is important in this case, because humans respond more positively to people they like, and if they perceive someone likes them, they are more likely to generate positive feelings towards that person and return the sentiment. It is a positive feedback loop that paves the way for people to form relationships based on perceived positivity from others. Additionally, using humour in particular can help greatly to establish liking and form closer bonds with other people [4]. It is one of the tools people use in the pursuit of feeling connected to others, and establishing closeness in a way that over time, can inspire trust. Thus, even humour has another layer that is not immediately apparent, and is linked to the way laughter is important in building relationships.

Three main theories have been developed in regards to humour and why people find things funny, and there is not one in particular that is seen as more accurate than the others. First is the superiority theory, which posits that when others are placed at a disadvantage or encounter misfortune, it is funny. The second theory is the benign violation theory; when one's dignity is violated in a way that is clearly not a threat, and is ultimately inconsequential, people will laugh.

The third theory is the incongruity and incongruity resolution theory, which in its essence is the idea that when someone is expecting a certain outcome and gets another instead, it will make them laugh. Such is the idea behind anti-jokes, which take well-known jokes, knock-knock jokes included, and flip them on their head by giving a too serious answer that is distinctively not what one is expecting $[5,6]$. A common example of an anti-joke is: "What is blue and smells like red paint? Blue paint." They are a form of comedy entirely their own, and though not everyone enjoys them, their startling but logical answers are often laughter-provoking. Not every person will enjoy every jokecomedy is subjective-but in certain cases, people will laugh at jokes that they do not even understand. It is a facet of social conformity that has been studied since the 1940s with many originators and much dispute as to which person was the one who invented the test, and it involves the human need to belong and be accepted within a group. One participant would be placed with a group of actors who would chat briefly to loosen them up, and then one of the actors would tell a joke that was clearly nonsensical, and the group would laugh as though they understood. The style of joke told would come to be known as a "no soap, radio" joke, because that was the punch line in each joke though the beginning could vary. Most of the time, the participant would laugh along with the group, and if probed about why they laughed, sometimes they could even come up with a logical explanation for why they laughed, even though it was just a nonsense joke. Studies such as this show how the content of humour takes a backseat to the social component of telling jokes and engaging with other people in ways that are meant to make them laugh. It is the bonding that is important, not the content.

\section{Conclusion}

Laughter in the form of comedy is not the most important necessarily, though it is often the first kind to come to mind when one thinks about the instances in which laughter would occur and has nuances that should not be overlooked, subtleties about its evolution that are not as well-known as the concept itself. It is much more rooted in a need to belong and a need to maintain bonds as social beings, and developed with the human species but not as a practice unique to humans. It was the most obviously present in the great apes, however; others, like rats, exhibit behaviour that has a similar function to laughter. It may not be a universal experience among all creatures, not much is, but it is a multifaceted concept with more functionalities than meet the eye. It has nuances that can be explored through concepts within the realm of social psychology, and has applications in other fields of psychology as well, in terms of the way laughter affects people and the people they spend time with.

\section{References}

1. Ross MD, Owren MJ, Zimmermann E (2010) The evolution of laughter in great apes and humans Communicative and Integrative Biology 3: 191-194.

2. McGraw P, Warner J (2014) Do Animals Have a Sense of Humor?

3. Askenasy J (1987) The Functions and Dysfunctions of Laughter. Journal Of General Psychology 114: 317.

4. Treger S, Sprecher S, Erber R (2013) Laughing and liking: Exploring the interpersonal effects of humor use in initial social interactions. European Journal of Social Psychology 43: 532-543.

5. Froese K (2013) Humour as the Playful Sidekick to Language in the Zhuangz Asian Philosophy 23: 137-152.

6. Herberman E (1999) Laughing matters Current Science 84: 10. 